\title{
Challenges and Strategies for Accessibility Research in the Global South: A Panel Discussion
}

Accessibility Research in the Global South

Giulia Barbareschi *

UCL Interaction Centre \& Global Disability Innovation Hub, London, UK Giulia.barbareschi.14@ucl.ac.uk

Swami Manohar Swaminathan

Microsoft Research India, Bangalore, India, manohar.swaminathan@ microsoft.com

André Pimenta Freire

Universidade Federal de Lavras, Lavras, Brazil, apfreire@dcc.ufla.br

Catherine Holloway

UCL Interaction Centre \& Global Disability Innovation Hub, London, UK c.holloway@ucl.ac.uk.

Over $80 \%$ of the 1 billion people with disabilities in the world live in the Global South, yet, most of the research at the intersection of disability and technology published across HCI venues is based in the Global North. With limited published research, and a large range of socio-cultural, practical and environmental differences across the Global South, HCI researchers and practitioners can encounter unexpected challenges when planning and conducting accessibility studies. The aim of this panel is to bring together three experienced academics who have conducted, managed and published impactful HCI research working with people with disabilities in various regions of the Global South from Latin America to East Africa and South Asia. Panelists will give an initial overview of their experiences conducting research with participants who had different disabilities and other relevant stakeholders, dedicating particular attention to the practical aspects commonly involved in research projects.

CCS CONCEPTS $\bullet$ Social and professional topics $\rightarrow$ People with disabilities $\bullet$ HCI Design and evaluation methods $\rightarrow$ Field Studies

Additional Keywords and Phrases: Accessibility, Disability, Global South, Ethics

ACM Reference Format:

First Author's Name, Initials, and Last Name, Second Author's Name, Initials, and Last Name, and Third Author's Name, Initials, and Last Name. 2018. The Title of the Paper: ACM Conference Proceedings Manuscript Submission Template: This is the subtitle of the paper, this document both explains and embodies the submission format for authors using Word. In Woodstock'18: ACM Symposium on Neural Gaze Detection, June 03-05, 2018, Woodstock, NY. ACM, New York, NY, USA, 10 pages. NOTE: This block will be automatically generated when manuscripts are processed after acceptance.

\footnotetext{
* Place the footnote text for the author (if applicable) here.
} 


\section{INTRODUCTION}

In the last decade, the field of accessibility research has grown almost exponentially and the HCI community has dedicated significantly more attention to exploring it $[8,12,14,21]$. The large majority of relevant studies take place in the Global North, despite over $80 \%$ of people with disabilities worldwide living in the Global South. The Global South is a large geopolitical space, encompassing different environmental, cultural and infrastructural circumstances, shaping a plurality of experiences of disability and technology access $[10,18,23,25]$. These can have little in common with the experiences of persons with disabilities in the Global North where infrastructure is more established and social norms different. For example, studies on how people with and without disabilities in the Global South use mobile phones in everyday lives identified how a complex network of human infrastructure enables users to bridge gaps linked to limited digital fluency, handset limitations, or inaccessible designs [2,3,11].

The lack of literature on accessibility research in the Global South, means that researchers working in the field, or approaching it for the first time, have limited possibilities to learn from the experiences of others, anticipate potential challenges and be familiar with strategies to promote collaborative approaches to foster synergies with local communities $[5,23,31]$. Moreover, the scarcity of accessibility relevant to the Global South can lead to lower levels of awareness about guidelines and procedures of how technology can be made more inclusive of people with disabilities [19].

It is worth remembering also that the comparatively low number of published articles by scholars and researchers from the Global South is indicative of deeper structural inequalities in the research community at large which are shaped by factors that include lack of funding, inadequate human resources, language barriers, procedural difficulties and unbalanced power dynamics [7]. To promote diversity and ensure that accessibility research truly presents a global picture, we should all strive to increase greater representation of the work of HCI researchers and practitioners working with people with disabilities in the Global South [5,10].

In our panel discussion we will explore the experiences of researchers that have conducted and published studies on accessibility, and technology use by people with disabilities in different areas of the Global South including Latin America, Sub-Saharan Africa and South Asia. Panelists will explore some of the practical challenges they have faced in their work and illustrate strategies and considerations that can be valuable for other researchers working at the intersection of disability and HCI in the Global South.

\section{POSITION STATEMENTS OF PANELISTS}

\subsection{Giulia Barbareschi (moderator)}

\subsubsection{Research Context.}

In the last few years, most of my work has been focused on understanding how innovation can help to increase access and impact of assistive technologies (ATs) for people with disabilities in the Global South. The majority of this work has been based in Kenya through the AT2030 programme which was founded by the UK Foreign Commonwealth Development Office and run by the Global Disability Innovation Hub. In the last decade, Kenya has made huge leaps when it comes to technological innovation, yet millions of people with disabilities across the country live in absolute poverty, are largely excluded by society and lack access to AT [13]. However, many of the people with disabilities living in Kenya's poorest areas can rely on a broader and stronger social support network compared to what is commonly observed in the Global North. 
Since 2019, I have worked on several research projects that aimed to leverage both technology innovation and existing social support networks to promote disability inclusion in Kenya. These include:

1. Projects looking to take advantage of new materials and manufacturing methods to develop more flexible and accessible service delivery models for AT [4]

2. Projects investigating how the use of mobile phone can help to promote disability inclusion and bridge physical accessibility barriers $[2,3]$

3. Projects looking at leveraging different forms of media to promote positive images of people with disabilities [27]

In my opening statement, I will bring up some point of discussion for the panel including challenges and strategies for the creation of partnerships with local organizations, managing the recruitment of participants and adapting research methods to cope with the challenges emerged during the COVID-19 pandemic.

\subsection{André Freire}

\subsubsection{Research Context.}

My research on digital accessibility has involved a number of efforts ranging from studies to understand the way in which people with disabilities interact with websites [26] and mobile devices [6,22], specific AT and applications [1,20,30], research on developers' and designers' perspectives on accessibility $[9,19]$ [ref] and organizational and systemic issues related to accessibility [24,28].

Recent studies in the ALCANCE laboratory have focused on the development and evaluation of smart home control systems for older adults and people with visual impairment, delving into specific issues in the Brazilian context. Our research has also focused on developing AT for reading mathematical formulae in Brazilian Portuguese and reading aids for people with dyslexia.

I have also worked with students and colleagues at the Graduate Programme in Public Administration to investigate the role of agencies such as the Public Prosecutor's Office in the surveillance of digital accessibility compliance in digital governmental services [24] and how public bodies specify accessibility requirements in public biddings and in-house implementation [28].

\subsubsection{Research Ethics, Public Funding and Participant Reimbursement in Brazil}

Having worked in the UK for more than 3 years during my $\mathrm{PhD}$, I noticed substantial differences in practical matters of the conduction of research, which significantly impacted the way research with people with disabilities is carried out. The first aspect is a much more bureaucratic process for ethical analysis. Projects with lower complexity may receive the first round of ethical analysis in 10-15 days in countries such as the UK or the US. In Brazil, however, most institutions will take 30 days, or much longer to provide the first round of reviews, frequently with another month after solving ethical pendencies.

Whilst in other counties there has been debate about how much to pay, or whether and when to pay research participants, this practice is explicitly outlawed by Brazilian legislation, which only allows reimbursement of "expenses that participants and possible escorts might have, when necessary, with aspects such as transport and subsistence" (Resolution CNS 466/2012).

This has a direct implication in the incentives that researchers can offer to research participants. Considering many of the pro-payment arguments that have been reported in countries that allow such practice, Brazil would actually systematically breach what is seen as an ethical duty of reimbursing participants for their time. The impediment to pay 
participants means that public research funding agencies do not allow researchers to allocate funds for this type of expense. Public funding also poses other limitations in Brazil. Aside from having caps for grants that are substantially lower than in other countries, even payments of transport and subsistence for research participants is not possible within the legal framework of most funding agencies. In most ordinary grants, researchers are only allowed to use public funds to reimburse expenses of team members of the project, or speakers in conferences, but not research participants.

\subsubsection{High Costs and Do-It-Yourself Culture}

People with disabilities in Brazil face many difficulties to purchase AT. The cost of licence of the JAWS screen reader in the UK is currently an average of $£ 700$, which accounts for approximately $70 \%$ of a month's salary for an individual employed on minimum wage. In Brazil, a recent quote for a JAWS license was rated at more than R $\$ 10,000$ which corresponds to nearly 10 months' worth of wage for a person living on minimum wage, which is the case for many people with visual impairments.

Before NVDA became available in 2006, such prohibitive costs for imported products meant that a Do-It-Yourself culture was established in the country. For example, DosVox and Virtual Vision were the first screen readers used by a substantial portion of Brazilians with visual impairment. However, such systems had significant limitations, limited compatibility and low stamina to catch up with systems like JAWS.

The way the Do-It-Yourself systems were implemented left long-lived marks even on the interaction styles many people with visual impairments use in Brazil. In my daily work with people with visual impairments in Brazil and in the UK, the differences in navigation strategies and the use of headings always struck me. The company Everis in Brazil confirmed my informal perception, and their replication of the survey conducted by WebAIM showed that, while 67,5\% of the predominantly North American and European participants reported using headings as their primary means to navigate in a long page, only $34,6 \%$ of Brazilian respondents reported the same behavior. These different navigational habits have a significant influence on accessibility guidelines and, ultimately, policy for accessibility in governmental websites.

Living in a non-English speaking country also has an impact on language support for screen readers. Research (still unpublished) from our group showed that almost no support was available to students with visual impairments for Mathematics classes. Support for Brazilian Portuguese reading of mathematical formulae has only been available in major screen readers recently, and is still unavailable in many.

\subsection{Cathy Holloway}

\subsubsection{Research Context.}

Within AT2030 HCI research helps to drive forward the evidence for policy and practice changes globally. We demonstrate that the value of AT is beyond the core functional enhancement of the person. Cathy is advancing GDI Accelerate, based on learning from setting up the first AT accelerator in Africa Innovate Now, and a global impact fund for AT. This will look to provide support for researchers and innovators globally to connect and ensure more ideas get from research to market.

GDI Hub exists to accelerate disability innovation for a fairer world and ultimately all our work is towards this aim. However, this is hard. At GDI Hub we have developed Disability Interactions (DIX) [15] to help guide HCI research projects. This has emerged, been tested, and evolved through AT2030 and our other projects. In this panel I will briefly present the DIX framework and dive into three lessons-learnt when developing it. 


\subsubsection{Positionality, partnerships \& power}

When developing projects about disability in the Global South it is essential researchers are reflective of their positionality, that partnerships are developed on the basis of equivalence, and power is shared.

At GDI Hub we do not believe any single group or organization will be able to change the course of history alone. Instead, we each have a role to play. Personally, I come to HCI research from the perspective of social justice - I want more people, especially poor people, to have access to more opportunities and better life outcomes. Therefore, power and the balance of power is of great importance. There are three areas where power can play out in research projects:

1. Geopolitical (and historical) power - this might seem beyond the scope of a HCI research project, but structural inequalities run deep at the intersection between disability and the Global South.

2. Power of partnership. Naturally, there will be many things I do not understand within a Global South context, assumptions I have and biases I hold, even those I am unaware of, should be challenged within a research project. Holding this knowledge, it is essential to grow meaningful partnership over the long term where each actor brings their own contribution which is valued and respected.

3. Power shifts. I work intentionally to ensure that greater numbers of disable people and Global South academics are able to participate and lead.

\subsubsection{Innovation and scaling solutions}

The disability interactions framework starts from acknowledging that disability inclusion is a wicked problem - and whilst such problems can seem impossible to solve, if we work to understand their complexity, we will create better solutions. We care about moving beyond just research to developing innovations which make it to market. To do this it is necessary to understand the need to measure value and usefulness and to create more open and scalable solutions:

1. Value \& Usefulness: Understanding the wider context of use of technology and how this is valued in society is essential. For example, we have seen locally manufactured devices are more valued than imported AT [4]. Moving beyond some functional measurements of use to more complex models of value also allows us to widen the economic case for investment in AT, moving it away from simple return on investment models of costs versus benefits to something more holistic.

2. Open \& Scalable: Open does not (necessarily) mean open-source, instead, we emphasize that technology should be developed in an open manner, rather than a hidden one. Being open to collaborations to help scale the reach and impact of the work.

Our work in AT2030 and across GDI Hub applies these principles, sometimes they work well, sometimes not so well, so we learn and adapt. I will be presenting some of this work and examples to stimulate debate.

\subsection{Manohar Swaminathan}

\subsubsection{Research Context.}

Over the past three years, we have been working with children and teachers in schools for the blind in India. The broad goals of the research are

1. Enable children with vision impairments to get an early introduction to computational thinking as part of their school curriculum

2. Empower the teachers in schools for the blind to be able to deliver the curriculum 
3. Create resources and curricular structure in schools for the blind to sustain such a curriculum.

Some of the publications from this work [16,17] will provide more details of the research context.

The following are three facets of the ongoing work that I will present during the panel discussion.

\subsubsection{Informed Consent}

The Ethics Board of Microsoft Research has standard forms and format for the entire process of recruitment, informed consent, and compensation for participation. When children and people with disabilities are involved in study additional flags are raised concerning risks to participants and the steps to mitigate them. The consent form is also modified to reflect these aspects. However, acquiring the consent from children with vision impairments poses many challenges, including language, agency of the child, capacity of guardians to understand the legalese and the possible pressure to participate because of the study compensation.

We address the above with a combination of measures: obtain consent from the school administration for the study, after detailed discussions with them about the nature of the study and work with the teachers and children identified by the study. Similarly explain to the teachers and ensure that a teacher (or teacher-assistant) is always present during the study. We instruct our research team to chat with the child and to convey that they can stop participating whenever they want and finally instruct our research team to stop the study if in their judgments the child is uncomfortable even if the child does not express any discomfort. We call the last part as informed assent from the child participant.

The research methodology that we employ, Ludic Design for Accessibility [29], by keeping play at the center also helps to ensure that the children and teachers actually enjoy the study activities.

\subsubsection{Compensation for user studies and benefit for the community}

Given the socio-economic status of the children and their parents, as well as the teachers in these schools, the 'standard' compensation suggested for similar studies (about US\$ 25 per participant, assuming that the participant spends an hour or two with the study) becomes comparable to the average monthly salary of the teacher (about US\$150 per month). Hence, we do not pay any compensation directly to either the children or the teachers in our study. Instead, we provide benefits to the school by providing digital skills training to the teachers and helping with the computing infrastructure of the schools. The goal is to ensure benefits accrue to the school, teachers and children beyond the actual research study.

\subsubsection{Dissonance between current HCI publication metrics and the above}

There are persistent tensions between the needs and processes of a HCI study (that aims to be presented in a conference like $\mathrm{CHI}$ or $\mathrm{CSCW}$ ) and the question of real long-term benefit to the target community. We have no perfect solutions to offer but highlight a few key challenges and some measures to meet those.

\section{SUMMARY}

The primary objective of this panel is to share experiences of accessibility research conducted in different geographies of the Global South. The hope is to start discussions and collaboration among the community, to learn from each other, and work together to make voices from the Global South heard in the HCI community.

\section{ACKNOWLEDGMENTS}

We want to thank all the collaborators, funders, partners and participants who have been involved in these studies. Without their help and support we would not have been able to learn and share these lessons. 


\section{REFERENCES}

[1] Luis Otávio de Avelar, Guilherme Camillo Rezende, and André Pimenta Freire. 2015. WebHelpDyslexia: A Browser Extension to Adapt Web Content for People with Dyslexia. Procedia Computer Science 67, (January 2015), 150-159. DOI:https://doi.org/10.1016/j.procs.2015.09.259

[2] Giulia Barbareschi, Ben oldfrey, Long Xin, Grace Nyachomba Magomere, Wycliffe Ambeyi Wetende, Carol Wanjira, joyce Olenja, Victoria Austin, and Catherine Holloway. 2020. Bridging the Divide: Exploring the use of digital and physical technology to aid mobility impaired people living in an informal settlement. In proceedings of the 22nd International ACM SIGACCESS Conference on Computers and Accessibility (ASSETS '20), Association for Computing Machinery, New York, NY, USA.

[3] Giulia Barbareschi, Catherine Holloway, Katherine Arnold, Grace Magomere, Wycliffe Ambeyi Wetende, Gabriel Ngare, and Joyce Olenja. 2020. The Social Network: How People with Visual Impairment use Mobile Phones in Kibera, Kenya. In Proceedings of the 2020 CHI Conference on Human Factors in Computing Systems (CHI '20), Association for Computing Machinery, Honolulu, HI, USA, 1-15. DOI:https://doi.org/10.1145/3313831.3376658

[4] Giulia Barbareschi, Sibylle Daymond, Jake Honeywill, Dominic Noble, Nancy N Mbugua, Ian Harris, Victoria Austin, and Catherine Holloway. 2020. Value beyond function: analyzing the perception of wheelchair innovations in Kenya. In proceedings of the 22nd International ACM SIGACCESS Conference on Computers and Accessibility (ASSETS '20), Association for Computing Machinery, New York, NY, USA.

[5] Giulia Barbareschi, Dafne Zuleima Morgado-Ramirez, Catherine Holloway, Swami Manohar Swaminathan, Aditya Vashistha, and Edward Cutrell. 2021. Disability Design and Innovation in Low Resource Settings: Addressing Inequality Through HCI. In Extended Abstracts of the 2021 CHI Conference on Human Factors in Computing Systems. Association for Computing Machinery, New York, NY, USA, 1-5. Retrieved September 6, 2021 from https://doi.org/10.1145/3411763.3441340

[6] Michael Crystian Nepomuceno Carvalho, Felipe Silva Dias, Aline Grazielle Silva Reis, and André Pimenta Freire. 2018. Accessibility and usability problems encountered on websites and applications in mobile devices by blind and normal-vision users. In Proceedings of the 33rd Annual ACM symposium on applied computing, 2022-2029.

[7] Fran M Collyer. 2018. Global patterns in the publishing of academic knowledge: Global North, global South. Current Sociology 66, 1 (January 2018), 56-73. DOI:https://doi.org/10.1177/0011392116680020

[8] Christopher Frauenberger. 2015. Disability and technology: A critical realist perspective. 89-96.

[9] Andre P. Freire, Cibele M. Russo, and Renata PM Fortes. 2008. A survey on the accessibility awareness of people involved in web development projects in Brazil. In Proceedings of the 2008 international cross-disciplinary conference on Web accessibility (W4A), 87-96.

[10] Anita Ghai, Vidhya Yella Reddy, and Swaminathan, Manohar. 2020. Assistive Technology Research and Disability Studies in the Global South: the Need for Synergy. (2020).

[11] Ishita Ghosh. 2016. Contextualizing Intermediated Use in the Developing World: Findings from India \& Ghana. In Proceedings of the 2016 CHI Conference on Human Factors in Computing Systems (CHI '16), Association for Computing Machinery, San Jose, California, USA, $355-359$. DOI:https://doi.org/10.1145/2858036.2858594

[12] Megan Hofmann, Devva Kasnitz, Jennifer Mankoff, and Cynthia L Bennett. 2020. Living Disability Theory: Reflections on Access, Research, and Design. In The 22nd International ACM SIGACCESS Conference on Computers and Accessibility (ASSETS '20), Association for Computing Machinery, New York, NY, USA, 1-13. DOI:https://doi.org/10.1145/3373625.3416996

[13] [C Holloway, V Austin, G Barbareschi, and F Ramos. 2018. Scoping Research Report on Assistive Technology. On the road for universal assistive technology coverage. Prepared by the GDI Hub \& partners for the UK Department for International Development. Global Disability Innvoation Hub (2018).

[14] Catherine Holloway. 2019. Disability Interaction (DIX): A Manifesto. Interactions 26, 2 (February 2019), 44-49. DOI:https://doi.org/10.1145/3310322

[15] Catherine Holloway, Kathrin Gerling, Christopher Power, Katta Spiel, Giulia Barbareschi, Anna Cox, and Paul Cairns. 2019. Disability Interactions in Digital Games: From Accessibility to Inclusion. In Extended Abstracts of the Annual Symposium on Computer-Human Interaction in Play Companion Extended Abstracts (CHI PLAY '19 Extended Abstracts), Association for Computing Machinery, New York, NY, USA, 835-839. DOI:https://doi.org/10.1145/3341215.3349587

[16] Gesu India, Aishwarya O, Nirmalendu Diwakar, Mohit Jain, Aditya Vashistha, and Manohar Swaminathan. 2021. Teachers' Perceptions around Digital Games for Children in Low-resource Schools for the Blind. In Proceedings of the 2021 CHI Conference on Human Factors in Computing Systems, 117.

[17] Gesu India, Geetha Ramakrishna, Joyojeet Pal, and Manohar Swaminathan. 2020. Conceptual Learning through Accessible Play: Project Torino and Computational Thinking for Blind Children in India. In Proceedings of the 2020 International Conference on Information and Communication Technologies and Development (ICTD2020), Association for Computing Machinery, New York, NY, USA, 1-11. DOI:https://doi.org/10.1145/3392561.3394634

[18] Lynn Kirabo, Elizabeth Jeanne Carter, Devon Barry, and Aaron Steinfeld. 2021. Priorities, Technology, \&amp; Power: Co-Designing an Inclusive Transit Agenda in Kampala, Uganda. In Proceedings of the 2021 CHI Conference on Human Factors in Computing Systems. Association for Computing Machinery, New York, NY, USA, 1-11. Retrieved September 6, 2021 from https://doi.org/10.1145/3411764.3445168

[19] Manoel Victor Rodrigues Leite, Lilian Passos Scatalon, André Pimenta Freire, and Marcelo Medeiros Eler. 2021. Accessibility in the mobile development industry in Brazil: Awareness, knowledge, adoption, motivations and barriers. Journal of Systems and Software 177, (July 2021), 110942. DOI:https://doi.org/10.1016/j.jss.2021.110942

[20] Mirella Alves de Lima, Daniela Rodrigues, Patricia Vasconcelos Almeida, Paula Christina Figueira Cardoso, and André Pimenta Freire. 2019. Análise de verbalizações de fórmulas matemáticas por professores com experiência no ensino de pessoas com deficiência visual / Analysis of mathematical formulas verbalizations by teachers with experience in teaching visually impaired people. REVISTA DE ESTUDOS DA LINGUAGEM 27, 3 (July 2019), 1371-1397. DOI:https://doi.org/10.17851/2237-2083.27.3.1371-1397 
[21] Kelly Mack, Emma McDonnell, Dhruv Jain, Lucy Lu Wang, Jon E. Froehlich, and Leah Findlater. 2021. What Do We Mean by “Accessibility Research"? A Literature Survey of Accessibility Papers in CHI and ASSETS from 1994 to 2019. In Proceedings of the 2021 CHI Conference on Human Factors in Computing Systems, 1-18.

[22] Delvani Antônio Mateus, Carlos Alberto Silva, Marcelo Medeiros Eler, and André Pimenta Freire. 2020. Accessibility of mobile applications: evaluation by users with visual impairment and by automated tools. In Proceedings of the 19th Brazilian Symposium on Human Factors in Computing Systems, 1-10.

[23] D Morgado Ramirez, Giulia Barbareschi, Maggie Donovan-Hall, Mohammad Sobuh, N Elayan, B Nakandi, R Ssekitoleko, J Olenja, G Magomere, and S Daymond. 2020. Disability design and innovation in computing research in low resource settings. Association for Computing Machinery.

[24] Aline Couto Oliveira, Leonardo Filipe da Silva, Marcelo Medeiros Eler, and André Pimenta Freire. 2020. Do Brazilian Federal Agencies Specify Accessibility Requirements for the Development of their Mobile Apps? In XVI Brazilian Symposium on Information Systems (SBSI'20), Association for Computing Machinery, New York, NY, USA, 1-8. DOI:https://doi.org/10.1145/3411564.3411643

[25] Joyojeet Pal, Priyank Chandra, Terence O’Neill, Maura Youngman, Jasmine Jones, Ji Hye Song, William Strayer, and Ludmila Ferrari. 2016. An Accessibility Infrastructure for the Global South. In Proceedings of the Eighth International Conference on Information and Communication Technologies and Development (ICTD '16), Association for Computing Machinery, Ann Arbor, MI, USA, 1-11. DOI:https://doi.org/10.1145/2909609.2909666

[26] Christopher Power, André Freire, Helen Petrie, and David Swallow. 2012. Guidelines are only half of the story: accessibility problems encountered by blind users on the web. In Proceedings of the SIGCHI Conference on Human Factors in Computing Systems. Association for Computing Machinery, New York, NY, USA, 433-442. Retrieved September 6, 2021 from https://doi.org/10.1145/2207676.2207736

[27] Shujaaz Inc. 2021. Final Narrative Report | AT2030 Programme. Retrieved September 6, 2021 from https://at2030.org/final-narrative-report/

[28] Siqueira, Dias, Rigatto, Carvalho, and Marques. 2020. Who Watches the Watchers? Accessibility of the Public Prosecutor's Office's Websites in Brazil and Implications for E-government Accessibility Surveillance Policies. Electronic Government: an International Journal in press (2020).

[29] Manohar Swaminathan and Joyojeet Pal. 2020. Ludic Design for Accessibility in the Global South. Assistive Technology and the Developing World", Editors: Michael Stein and Jonathan Lazar. Oxford university Press. Preprint at. https://www. microsoft. com/en-us/research/publication/ludic-designfor-accessibility (2020).

[30] Letícia Diniz Tsuchiya, Lucas Fiorini Braga, Otavio de Faria Oliveira, Raphael Winckler de Bettio, Juliana Galvani Greghi, and André Pimenta Freire. 2021. Design and evaluation of a mobile smart home interactive system with elderly users in Brazil. Personal and Ubiquitous Computing 25, (2021), 281-295.

[31] Aditya Vashistha, Richard Anderson, and Shrirang Mare. 2018. Examining Security and Privacy Research in Developing Regions. In Proceedings of the 1st ACM SIGCAS Conference on Computing and Sustainable Societies (COMPASS '18), Association for Computing Machinery, New York, NY, USA, 1-14. DOI:https://doi.org/10.1145/3209811.3209818 